\title{
A imagem da imprensa sobre a emigração brasileira
}

\author{
HELION PÓVOA NETO
}

\section{O significado da emigração}

$\mathrm{O}$ FENÔMENO RECENTE da emigração de brasileiros representa uma descontinuidade histórica num país formado por expressivos fluxos imigratórios, perceptíveis até os anos 1960. Hoje, o Brasil contribui decisivasivamente para a imigração latino-americana nos Estados Unidos, em determinados países europeus (Portugal, Espanha, Itália) e no Japão. Digna de nota é também a mobilidade rumo a países fronteiriços, em especial o Paraguai, mas também Bolívia, Suriname e Guiana Francesa.

Do ponto de vista demográfico, bastaria um saldo migratório negativo para caracterizar uma situação de emigração. ${ }^{1}$ Porém, o que nos parece digno de ênfase - e merecedor das observações a seguir - é o significado político e cultural desse fato numa nação, por assim dizer, "acostumada" a se pensar como terra de oportunidades, formada com a contribuição do trabalho de estrangeiros.

A classificação de um país como "de emigração" ou “de imigração" costuma se associar a um diagnóstico que, por simplista que seja, possui grande força: o de que as nações receptoras de imigrantes teriam atrativos derivados da qualidade de vida disponível à sua população, enquanto as terras "expulsoras" de emigrantes apresentariam graves problemas de ordem social, política e econômica.

Sabemos bem como essa classificação binária deixa de ser significativa no contexto da globalização, quando os movimentos de diversas escalas e durações se aceleram, quando as facilidades para o deslocamento se multiplicam (acompanhadas, é verdade, de importantes iniciativas de repressão aos fluxos migratórios), quando, enfim, a idéia de mobilidade, de flexibilidade, é erigida como valor a ser perseguido por indivíduos e economias.

A verdade é que assistimos à transformação de áreas tradicionalmente de emigração em terras de imigração, como no caso dos países europeus mediterrâneos. Ao mesmo tempo, outras áreas do planeta tornam-se lugar de trânsito para migrantes que pretendem atingir países de imigração. Países norte-africanos, como Marrocos e Líbia, europeus do Leste, como a República Checa e a Romênia, ilhas, como Malta, Chipre, a Sicília italiana e as Canárias espanholas, definem-se, do ponto de vista migratório, como "plataformas" para atingir a Europa Central e Ocidental. Eventualmente, as medidas de controle ao norte e a oeste contra tais migrantes acabam por transformar tais espaços de trânsito em 
áreas de estabelecimento duradouro ou mesmo permanente. O mesmo ocorre com o México, passagem para migrantes latino-americanos a caminho dos Estados Unidos. Ou seja, emigração, imigração, trânsito não são situações fixas, e sim sujeitas a processos de transição.

Tais exemplos deveriam nos munir de cautela contra as classificações, além de alertar para a considerável complexidade dos contextos atuais de deslocamento espacial. Encontra-se, porém, de tal forma estabelecido o imaginário da migração como busca de melhores condições de vida na área de destino e/ou de rejeição a situações de opressão e carência na área de partida, que por vezes continuamos a trabalhar com as mesmas associações.

O objetivo da presente contribuição será enfatizar a nova situação brasileira de país de emigração como um fato social e político que vem sendo progressivamente construído por meio de uma mudança nas representações sociais relativas aos deslocamentos internacionais de população. Selecionamos, como via de acesso a essa mudança, um material constituído por notícias veiculadas nos últimos cinco anos.

Ao tratarem do tema da migração, bem como de qualquer outro, os meios de comunicação fazem uso do discurso não-acadêmico (mesmo que eventualmente informado por membros da academia), utilizando a informação transformada em notícia como meio para conquista e consolidação de posições ante o mercado dos leitores. Para isso, podem apelar ao recurso da reiteração de idéias já estabelecidas e, curvando-se ao imperativo da informação breve e imediata, não privilegiar o aprofundamento analítico sobre processos sociais com alto grau de complexidade.

Acreditamos, no entanto, que, sendo jornais e revistas veículos preferenciais na transmissão de informações junto ao público sobre fenômenos que ultrapassam a escala local e nacional, uma análise da veiculação de notícias a respeito de um tema como a migração poderia contribuir para uma compreensão das mudanças na sua percepção. ${ }^{2}$

No caso brasileiro, os primeiros trabalhos acadêmicos publicados sobre o novo fenômeno da emigração de brasileiros e os processos a ela associados vieram à luz no final dos anos $1980 .{ }^{3}$ Nas décadas seguintes, aos pesquisadores responsáveis por tais análises pioneiras juntaram-se outros, sendo possível hoje afirmar o estudo das comunidades de brasileiros no exterior como plenamente reconhecido pela academia. ${ }^{4}$

A presente contribuição diferencia-se de tais estudos, já que pretende apenas assinalar, para um período de tempo determinado - 2001 a $2005-$, que tipo de atenção a imprensa brasileira vem dedicando ao fenômeno da emigração de brasileiros. Para tanto, analisamos e classificamos o noticiário conforme os anos, as áreas geográficas de referência e as ênfases em alguns temas selecionados, que foram os seguintes:

- condições de vida e trabalho de brasileiros no exterior; 
- remessas de emigrantes brasileiros;

- detenção, prisão, deportação de brasileiros por problemas de documentação ou travessia ilegal de fronteira; ${ }^{5}$

- envolvimento de brasileiros em tráfico de seres humanos, exploração sexual ou prostituição; 6

- outros temas associados a brasileiros no exterior. ${ }^{7}$

Crescimento na ocorrência do tema “emigração de brasileiros"

A coleta de material foi realizada basicamente por meio de edições eletrônicas de jornais. ${ }^{8}$ Ainda que sem pretensão estatística quanto à presença do tema na imprensa brasileira em geral, para o período considerado, acreditamos ter conseguido captar algumas descontinuidades e variações de ênfase perceptíveis no noticiário como um todo. ${ }^{9}$

Ao observarmos a Tabela 1, elaborada para uma aproximação inicial a essas variações, verificamos o crescimento da ocorrência da emigração brasileira no noticiário, aparecendo em 2005 com o triplo das referências verificadas em 2000. Acreditamos que isso expressa uma atenção crescente da imprensa ao fenômeno, embora não possamos, conforme já alertado, valorizar em demasiado a expressão estatística de tal variação, mas apenas algumas ênfases.

Um exemplo de como essas podem ter refletido, mesmo parcialmente, algumas descontinuidades está em como os temas associados à criminalidade de brasileiros no exterior e à sua participação em redes de tráfico de pessoas ganharam espaço ao longo do período. Evidentemente, isso pode ser associado à crescente visibilidade de tais temas não apenas no Brasil, mas no mundo como um todo. Mas expressa também, provavelmente, algumas mudanças na situação dos emigrantes brasileiros e nas suas estratégias de emigração.

Tomando-se o caso norte-americano, sabe-se que, até recentemente, as comunidades brasileiras não eram objeto de maior preocupação das autoridades locais, por seu grau relativamente baixo de envolvimento com atividades criminosas e pela sua reduzida visibilidade externa. Porém, o crescimento da presença brasileira, as novas vias de acesso empregadas (travessia da fronteira sul, em detrimento da entrada por via aérea) e a intensificação das medidas de controle sobre estrangeiros após o 11 de Setembro parecem ter modificado esse quadro. Notícias sobre aviões fretados pelo governo norte-americano para repatriação de brasileiros em situação irregular começaram a se tornar mais e mais freqüentes.

Também na Europa, o desenvolvimento de redes clandestinas de facilitação à migração (via travessia ilegal de fronteiras ou, mais importante no caso em foco, falsificação de documentos) vem contando cada vez mais com a presença de brasileiros no noticiário sobre elas. No caso europeu, as referências à prostituição e à exploração de imigrantes (destaque para mulheres) apareceram com freqüência crescente ao longo do período.

As remessas de brasileiros no exterior e suas repercussões nas áreas que as receberam foram outro tema em que se verificou crescimento, mesmo sem 
alcançar o grande número de referências verificadas nos demais temas já mencionados. As informações sobre um montante superior a cinco bilhões de dólares que teriam sido remetidos ao país por emigrantes no exterior atraíram a atenção da imprensa e mereceram destaque no noticiário. ${ }^{10}$

As ênfases e os silêncios do noticiário na abordagem dos emigrantes brasileiros não devem, todavia, ser tomados como indicadores absolutos da intensificação, arrefecimento ou mudança qualitativa dos processos migratórios. Como será destacado mais adiante, o exame do material de imprensa indica claramente como eventos excepcionais e interesses mercadológicos podem também ditar a atenção do noticiário.

Tabela 1 - Ocorrências do tema "brasileiros no exterior" no material examinado, por ano

\begin{tabular}{l|r|r|r|r|r|r}
\hline & 2001 & 2002 & 2003 & 2004 & 2005 & total \\
\hline $\begin{array}{l}\text { Condições de vida e } \\
\text { trabalho de brasileiros } \\
\text { no exterior }\end{array}$ & 6 & 6 & 3 & 13 & 16 & 44 \\
\hline $\begin{array}{l}\text { Remessas de } \\
\text { emigrantes brasileiros }\end{array}$ & 2 & 1 & 3 & 1 & 8 & 15 \\
\hline $\begin{array}{l}\text { Detenção, prisão, } \\
\text { deportação de } \\
\text { brasileiros por } \\
\text { problemas de } \\
\text { documentação ou } \\
\text { travessia ilegal de } \\
\text { fronteira }\end{array}$ & 10 & 5 & 4 & 8 & 23 & 50 \\
\hline $\begin{array}{l}\text { Envolvimento de } \\
\text { brasileiros em } \\
\text { tráfico de seres } \\
\text { humanos, exploração } \\
\text { sexual ou prostituição }\end{array}$ & 8 & - & - & 10 & 21 & 39 \\
\hline $\begin{array}{l}\text { Outros temas } \\
\text { associados a brasileiros } \\
\text { no exterior }\end{array}$ & 7 & 8 & 4 & 10 & 24 & 53 \\
\hline \begin{tabular}{l} 
Total \\
\hline
\end{tabular} & 33 & 20 & 14 & 42 & 92 & 201 \\
\hline
\end{tabular}

\section{O tema da emigração segundo área geográfica de destino}

As áreas que apareceram com destaque no noticiário como lugar de destino de emigrantes brasileiros foram: Estados Unidos, México, Japão, Portugal, Espanha, Itália, França, Irlanda, Reino Unido, Paraguai, Bolívia, fronteira norte (Colômbia, Suriname, Guiana Francesa) e outras com menor número de ocorrências. O material de imprensa examinado foi classificado de acordo com cada uma delas, e a seguir tecemos algumas observações a respeito dos temas abordados. ${ }^{11}$ 
Uma observação inicial sobre a distribuição geográfica do noticiário, tal como expressa pela Tabela 2, é a de que os Estados Unidos concentraram a maior parcela, alcançando cerca de um terço de todo o material. O significativo e crescente contingente de brasileiros nesse país, somado ao fato da irregularidade da presença e das vias alternativas para emigração através da fronteira sul dos Estados Unidos acarretaram, também, um noticiário sobre prisões e deportações a partir do México, cada vez mais uma área de trânsito para o território norte-americano.

Tabela 2 - Ocorrências do tema "brasileiros no exterior", no material examinado, por área geográfica, durante os anos de 2001 a 2005

\begin{tabular}{l|c}
\hline Área Geográfica & Ocorrências \\
\hline Exterior em geral $^{*}$ & 27 \\
\hline Estados Unidos & 74 \\
\hline México & 9 \\
\hline Japão & 10 \\
\hline Portugal & 18 \\
\hline Espanha & 11 \\
\hline Itália, França e Irlanda & 4 \\
\hline Reino Unido & 19 \\
\hline Paraguai e Bolívia & 10 \\
\hline Fronteira norte & $\mathbf{5}$ \\
\hline Outros & $\mathbf{1 4}$ \\
\hline Total & $\mathbf{2 0 1}$ \\
\hline
\end{tabular}

* Sem referência principal a um determinado país.

** Colômbia, Suriname e Guiana Francesa.

Muitas notícias se referiram à emigração para o exterior em geral, e nesse grupo apareceu com destaque o tema do envolvimento de brasileiros com tráfico de pessoas e exploração sexual. Foram referências tanto ao movimento para áreas fronteiriças, em geral com destaque para a exploração de menores (Folha de S.Paulo, 16.5.2005), quanto à atuação de quadrilhas internacionais envolvidas com aliciamento de mulheres e falsificação de documentos (Correio Braziliense, 6.10.2004; O Estado de S. Paulo, 26.2.2005; Folha de S.Paulo, 31.7.2005 e 5.10.2005). O país apareceu também como sujeito à pressão de governos estrangeiros, em especial os Estados Unidos, no sentido de um combate mais rigoroso ao tráfico (Folha de S.Paulo, 13.7.2001 e 4.6.2005; BBC Brasil, 3.6.2005).

Nesse noticiário que colocou em relação o Brasil e seu espaço além das fronteiras, surgiram análises e entrevistas com especialistas a respeito da transição demográfica do país e do arrefecimento das migrações internas ( $O$ Estado de Minas, 28.1.2001). O fenômeno da emigração foi freqüientemente apresentado como nova questão merecedora de preocupação nacional, uma vez reduzidos os 
deslocamentos internos e verificada a queda do crescimento vegetativo. Violência e desemprego no Brasil foram apontados como causas da emigração, sugerindo a inserção do tema em meio à pauta de temas reconhecidos no país como politicamente centrais (NoMinimo, 26.3.2004).

Outro dos temas abordados com certa freqüência foi a chamada "fuga de cérebros", indicando exemplos de economias em que tal fenômeno é reconhecido há mais tempo, como a Índia. No caso brasileiro, foram apresentados os bolsistas de instituições de financiamento como especialmente sujeitos a um possível não-retorno, uma vez finalizados os estudos no exterior (Valor, 5.7.2001; $O$ Estado de S. Paulo, 31.10.2002, 21.12.2002 e 25.10.2005).

Quando enfocamos em particular o caso dos Estados Unidos, país com o maior número de notícias no material analisado, o predomínio absoluto é, conforme já assinalado, de referências a problemas de ilegalidade e clandestinidade na travessia da fronteira sul do país ou na permanência ilegal de brasileiros com visto de turista. Ao longo do período estudado, notamos claramente um crescimento da primeira modalidade de menção em detrimento da segunda, já que a política de maior rigor na concessão de vistos vem forçando os brasileiros a apelarem para a tentativa de entrada via México, geralmente com auxílio de contrabandistas, os chamados coyotes ou polleros.

Os totais de emigrantes presos apareceram como crescentes, apresentando recordes paulatinamente quebrados, estando já os brasileiros entre as dez comunidades de imigrantes mais afetadas por deportações nos Estados Unidos (O Estado de S. Paulo, 2.6.2001, 3.6.2001 e 20.9.2002; Terra, 22.6.2001; $O$ Estado de Minas, 30.8.2002; Folha de S.Paulo, 13.7.2004 e 16.1.2005; Zero Hora, 15.3.2005; UOL Noticias, 6.7.2005). A associação habitual entre esses deportados e os naturais do Estado de Minas Gerais (em especial a cidade de Governador Valadares) foi relativizada por reportagens sobre os goianos deportados, indicando essa nova área de origem para a emigração (Jornal Opção - Goiânia -, 8.14.2.2004). A organização de esquemas de facilitação ilegal à emigração baseadas em Criciúma, Santa Catarina, expôs também o papel mais recente dessa cidade como nó na organização de redes clandestinas da migração para o exterior (NoMinimo, 26.3.2004; Jornal da Manhã - Criciúma -, 5.10.2005).

A menção a brasileiros nos Estados Unidos se expandiu, no período assinalado, de modo a incluí-los mesmo em um evento como os atentados terroristas do 11 de Setembro. Por conta da onda de repressão a árabes, muçulmanos e descendentes, um brasileiro foi preso, ao que tudo indica por conta de sua origem árabe (Folha de S.Paulo, 11.10.2001; Folha Online, 25.10.2001).

Sendo o número de brasileiros residentes apresentado como crescente, a comunidade compareceu até mesmo em meio ao noticiário referente às eleições presidenciais de 2002, numa menção à campanha que o Partido dos Trabalhadores teria feito em áreas de grande concentração de possíveis eleitores, como Nova York (Folha de S.Paulo, 15.9.2002). O tema da emigração esteve presente também por ocasião da viagem do candidato Luiz Inácio Lula da Silva à cidade 
de Governador Valadares (Minas Gerais). Associando a saída de brasileiros daquela região ao desemprego, o presidenciável destacou a prioridade de geração de empregos, caso eleito, como uma possibilidade de reversão do fluxo para o exterior ( $O$ Estado de S. Paulo, 23.9.2002).

Encerrando as considerações a respeito da emigração para os Estados Unidos, cabe assinalar o fato óbvio, mas nunca excessivamente lembrado, de que a presença e o peso de determinados temas na grande imprensa não são orientados apenas por uma avaliação objetiva quanto à pertinência de determinado tema. Nem mesmo o interesse de grupos politicamente organizados ou do Estado bastaria para compor o quadro de determinações que orientam as ênfases do noticiário. Motivos comerciais também se fazem sentir, e exemplo eloqüente esteve no destaque conferido pelos veículos das Organizações Globo ao tema da emigração de brasileiros, em especial para os Estados Unidos, no decorrer da telenovela veiculada de março a novembro de 2005, que tinha nesse fenômeno um de seus focos dramáticos principais. O período durante o qual a telenovela esteve no ar foi marcado por uma ênfase incomum do noticiário à temática, tendo sido aliás alimentadas polêmicas quanto a se a telenovela apenas retrataria o fenômeno migratório ou, mais que isso, chegaria até mesmo a estimulá-lo (Folha de S.Paulo, 5.5.2005 e 6.5.2005). ${ }^{12}$

Antes de entrarmos nas áreas de destino européias, vale destacar que, quando se trata de migrações, o México apareceu no noticiário da imprensa brasileira como área de passagem para brasileiros a caminho dos Estados Unidos $(O$ Estado de Minas, 17.1.2001; Folha de S.Paulo, 16.1.2005 e 5.5.2005; UOL Notícias, 24.7.2005). A pressão norte-americana para um engajamento mexicano no maior controle de suas fronteiras não só ao norte como também ao sul (com a Guatemala e, por extensão, América Central) tem forçado o Estado mexicano à situação de aliado no esforço de retenção de parte do fluxo de latino-americanos que se dirigem aos Estados Unidos. Daí a veiculação de notícias nas quais o governo mexicano anunciou maior rigor quanto ao controle da entrada de brasileiros (inclusive com a exigência de visto) (Folha de S.Paulo, 6.5.2005) e propôs "pactos" de colaboração com o Brasil no campo da emigração (Folha de S.Paulo, 15.7.2004 e 18.10.2005).

Dentre os países europeus, Portugal e Reino Unido receberam, como áreas de destino para emigrantes, as menções mais numerosas por parte da imprensa brasileira. No caso português, tendo os brasileiros, durante o período considerado, se tornado a comunidade estrangeira mais numerosa no país, o fato motivou diversas reportagens a respeito de suas condições de vida e trabalho $(O$ Estado de S. Paulo, 9.9.2001; Paraná-Online, 9.9.2001).

Foram freqüentes, também, referências à política portuguesa de imigração, nem sempre favorável aos brasileiros, apesar das promessas quanto a um status especial para eles. A visita do presidente Luiz Inácio Lula da Silva a Portugal mereceu diversas matérias, incluindo seu apelo para uma anistia às multas que incidiam sobre brasileiros em situação irregular. A imprensa também 
registrou, mais recentemente, o não-cumprimento de promessas nesse sentido feitas pelo governo português por ocasião daquela visita (Terra, 4.10.2001; O Globo, 7.8.2002; BBC Brasil, 28.5.2004, 9.7.2004 e 12.7.2004; Folha de S.Paulo, 14.10.2005). No que se refere a Portugal, registre-se finalmente que as menções a redes clandestinas de migração, ligadas ou não à prostituição, se mostraram crescentes durante o período assinalado (O Estado de S. Paulo, 7.8.2001 e 4.2.2003; Folha de S.Paulo, 10.6.2005).

Em nenhum país, porém, a imagem dos brasileiros parece se associar tanto à questão da prostituição quanto na Espanha, ao menos quando se toma como fonte a imprensa do Brasil. ${ }^{13}$ Foram muitas as referências a redes de tráfico e de exploração sexual de brasileiras, freqüentemente em conjunto com mulheres de outras nacionalidades. Vale assinalar também a presença do Estado de Goiás como área de origem no aliciamento de parcela significativa das mulheres abordadas nas reportagens (UOL Noticias, 11.2.2004; Folba de S.Paulo, 1.6.2004, 4.12.2004 e 15.4.2005; BBC Brasil, 9.6.2004; Jornal do Brasil, 1.9.2004; O Estado de S. Paulo, 26.2.2005). ${ }^{14}$

Além dessas referências, emigrantes brasileiros na Espanha apareceram também em reportagens que destacavam a ilegalidade de sua situação e o temor às deportações (embora essas jamais tenham aparecido com o mesmo destaque do caso norte-americano). Por ocasião da grande anistia de 2004, os brasileiros foram noticiados como um dos grupos beneficiados, atingindo mais de dez mil regularizados pela medida (Jornal do Brasil, 18.3.2001; Folha de S.Paulo, 24.6.2001 e 3.6.2005).

Pode-se afirmar que, dentre os países europeus, a Grã-Bretanha conheceu o maior crescimento, para o período estudado, em menções na imprensa sobre a imigração brasileira, em especial a de caráter irregular. Fenômeno ainda relativamente pouco estudado, mesmo pela academia, ${ }^{15}$ sua intensificação nos últimos anos parece estar conectada à intensificação dos controles de entrada nos Estados Unidos. A Grã-Bretanha teria funcionado, segundo essa hipótese, como uma espécie de destino alternativo para aqueles rechaçados pela imigração norte-americana ou desestimulados a tentar o ingresso naquele país ( $B B C$ Brasil, 28.11.2002).

No ano de 2005, as informações sobre a presença brasileira em Londres conheceram notável crescimento de veiculação em razão do assassinato de um brasileiro, confundido com um terrorista pela polícia britânica. Antes, porém, desse evento, já saíam matérias a respeito do grupo, relatando suas condições de sobrevivência e a preocupação das autoridades britânicas com o crescimento da comunidade (BBC Brasil, 2.9.2003 e 4.9.2003; O Estado de S. Paulo, 25.6.2004). As estratégias de permanência, que incluem vendas de vagas no mercado de trabalho, casamentos arranjados e falsificação de documentos, foram objeto de diversas reportagens (BBC Brasil, 17.9.2004 e 24.9.2004; Zero Hora, 13.6.2005), assim como a prisão e deportação de envolvidos com tais práticas ilícitas ( $B B C$ Brasil, 14.8.2003 e 22.8.2003; Folha de S.Paulo, 13.2.2005, 31.7.2005 e 5.11.2005). 


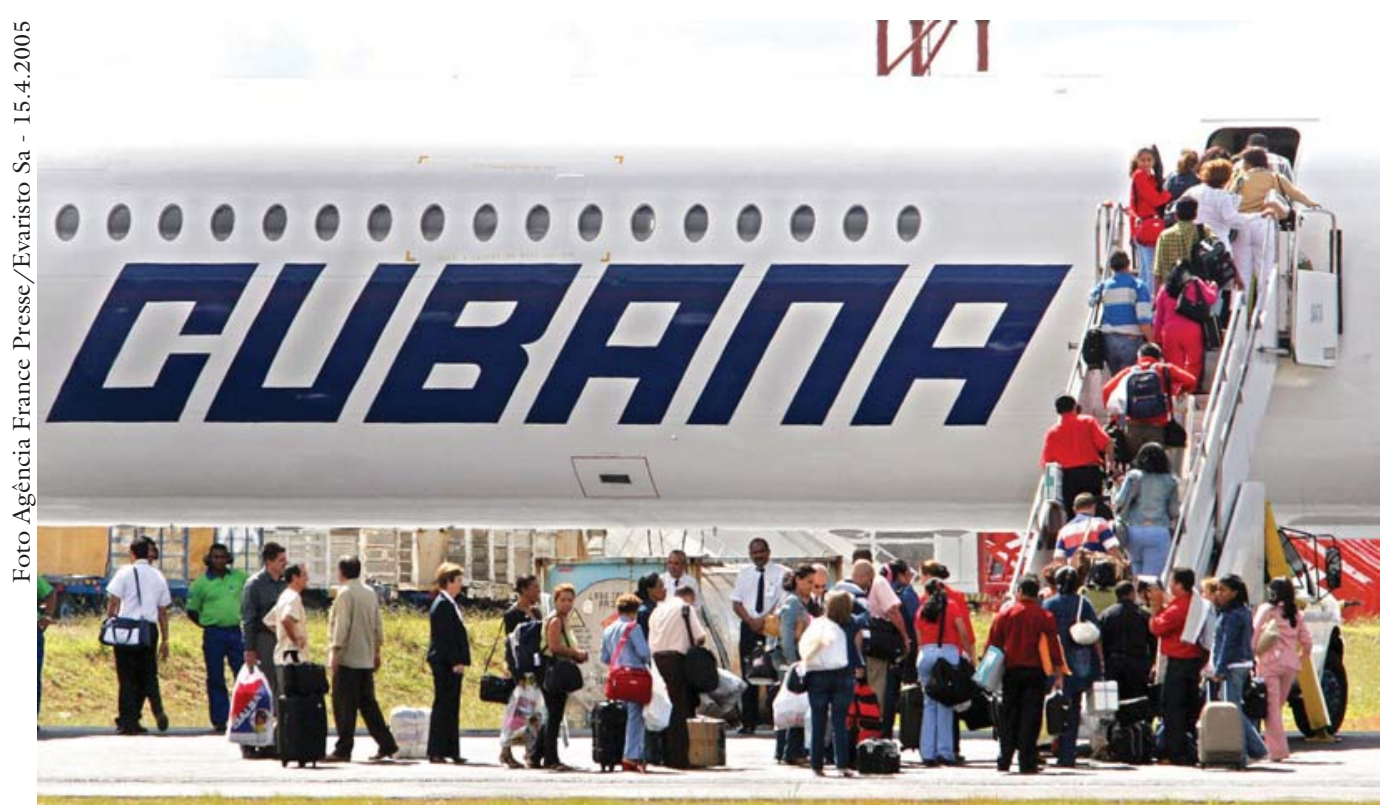

Foi noticiado embarque de 69 médicos cubanos cujos diplomas não foram reconbecidos no Brasil.

$\mathrm{O}$ evento catalisador na intensificação do noticiário a respeito dos brasileiros na Grã-Bretanha foi, porém, a execução do brasileiro Jean Charles de Menezes por policiais em Londres, em julho de 2005. Um grande volume de reportagens, análises e crônicas foi publicado no Brasil a respeito, trazendo o fato para o tema da deterioração da vida nacional, cujas condições desfavoráveis - em especial o desemprego e a violência - estariam levando milhares de jovens como Jean Charles a tentar a vida no exterior. O tema da violência, em particular, apareceu de forma a sublinhar o paradoxo da sociedade britânica, que para os brasileiros apareceria como menos sujeita a tal problema, impressão esta desmentida pelos fatos ( $O$ Globo, 23.7.2005, 25.7.2005, 28.7.2005; Folha de S.Paulo, 24.7.2005; Jornal do Brasil, 27.7.2005).

Ainda com relação à Europa, pode-se assinalar informação sobre a presença de brasileiros para uma área de destino sobre a qual ainda se dispõe de reduzida informação. Trata-se da Irlanda, onde, segundo o noticiário disponível, existe um grupo considerável de trabalhadores oriundos do Estado de Goiás trabalhando no setor de comercialização ligado à carne (BBC Brasil, 30.4.2004). ${ }^{16}$

Ao lado dos Estados Unidos e da Europa Ocidental, o Japão apareceu como o outro destino da migração transcontinental de brasileiros. A tônica do noticiário sobre os dekasseguis girou freqüentemente em torno da magnitude da presença de emigrantes naquele país (O Estado de S. Paulo, 1.7.2001), que durante o período analisado esteve sempre acima de 250 mil pessoas. Também o tema das remessas foi bastante presente (Folha de S.Paulo, 29.6.2003).

Embora de forma menos importante do que no caso das áreas geográficas anteriores, já que a emigração dekassegui é quase que totalmente regulamentada, também para o caso do Japão houve registro de casos de falsificação de documentos com vistas à obtenção de permissões de residência (Jornal do Brasil, 
19.1.2001). Mais numerosas foram as referências à criminalidade de brasileiros, em especial de jovens (Folha de S.Paulo, 23.2.2003).

Após a migração transcontinental, cabe tratar dos territórios nacionais fronteiriços ao Brasil, para onde os deslocamentos populacionais são de natureza bastante diferente, já que muitas vezes se deram como prolongamento de processos migratórios internos. Disso é exemplo o caso dos brasileiros no Paraguai. O termo "brasiguaios" nomeia principalmente os agricultores que cruzaram a fronteira a partir da década de 1970, e a eles se referiram notícias de conflitos de terra e de projetos de expulsão dos que ocupam áreas agrícolas próximas à fronteira leste paraguaia (O Estado de S. Panlo, 11.4.2001; Gazeta do Povo - Curitiba -, 21.10.2002; Zero Hora, 5.4.2005).

No final do período enfocado, porém, começaram a surgir notícias envolvendo ameaças e atos de expulsão de brasileiros habitantes de áreas urbanas paraguaias próximas à fronteira, em geral envolvidos com comércio legal e contrabando de mercadorias para o Brasil. Medidas que foram interpretadas pela maior parte dos veículos de imprensa como de retaliação a um maior rigor, por parte do Brasil, no controle da fronteira, o que estaria prejudicando o comércio do lado paraguaio (Zero Hora, 30.3.2005 e 3.4.2005; Correio do Povo - Porto Alegre -, 23.3.2005).

Finalmente, tal como em outras áreas adjacentes à fronteira brasileira, ocorreram para o caso do Paraguai numerosas referências ao tráfico associado à exploração sexual, principalmente de mulheres, inclusive menores de idade ( $\mathrm{Pa}$ raná Online, 2.8.2001; Folha de S.Paulo, 16.5.2005). Tais casos foram noticiados também em outras fronteiras, tais como no Uruguai, Argentina e Suriname.

A presença irregular de brasileiros em países da fronteira amazônica norte esteve associada principalmente ao garimpo (referências a Colômbia, Suriname e Guiana Francesa). A presença de garimpeiros em tais países indica uma outra forma de emigração que constitui um desdobramento de movimento migratório inicialmente interno ao Brasil. Assim como a presença de brasiguaios no Paraguai representou uma forma de expansão da agricultura camponesa e empresarial desalojada de terras brasileiras, o garimpo nos países citados resulta de movimentos da frente mineradora que extravasaram a fronteira nacional, em busca de condições de exploração não sujeitas aos entraves legais existentes no lado brasileiro. Como de hábito nos garimpos amazônicos, aí também a atividade foi acompanhada pelo deslocamento de prostitutas, o que explica as freqüentes referências a tráfico e exploração sexual em meio às comunidades de brasileiros (Jornal da Tarde, 24.7.2001; Jornal do Brasil, 2.1.2002; Folba de S.Paulo, 21.9.2004 e 22.12.2004).

\section{Observações finais}

Encerrado o breve percurso por alguns dos temas que têm aparecido como característicos da emigração de brasileiros para o exterior, cabem duas observações finais que retornam ao início deste trabalho. 
A primeira observação está em que o termo migração (bem como seus relacionados emigração e imigração), ${ }^{17}$ extremamente abrangente como é, nomeia nos casos abordados situações bastante diversas em termos da relação dos migrantes com a sociedade receptora, com as condições do mercado de trabalho local, com a situação de legalidade ou ilegalidade, com as formas de preconceito e rejeição encontrada e, mesmo, com as maneiras pelas quais são encarados em suas áreas de origem.

Esse "olhar" da nação para com seus emigrantes não foi sempre o mesmo em todas as sociedades. Historicamente, encontramos representações de emigrantes como colonizadores, difusores da economia e da cultura, emissários dos valores de sua civilização. Outras foram as situações em que a existência do emigrante representou a evidência poderosa das dificuldades de sobrevivência de uma população nos marcos de seu próprio território e de suas instituições. ${ }^{18}$

A transição de um padrão migratório a outro implica a revisão desse imaginário, favorável ou desfavorável à emigração (e, por vezes, ambíguo), processo que tem seu tempo próprio e que lida com representações sociais. No caso brasileiro, encontra-se em vias de mudança a percepção (por mais idealizada que seja) de uma história nacional de acolhimento ao estrangeiro e de percepção de espaços que o imigrante podia e devia ocupar. Era a visão de um território supostamente marcado por "vazios" a preencher de civilização, de um mercado de trabalho a reclamar "braços" para seu pleno desenvolvimento. Trata-se agora de imaginar uma história nova, de nação de emigrantes, e talvez os meios de comunicação estejam desempenhando um papel nesse processo de reconstrução.

A outra observação diz respeito à hipótese da generalização progressiva, para os brasileiros no exterior, da sua designação como emigrantes, unificando uma profusão de termos - e de situações concretas -, nos quais existiam antes de tudo dekasseguis no Japão, "brazucas" nos Estados Unidos, dentistas em Portugal, brasiguaios, "brasivianos” e garimpeiros nos países de fronteira.

A diversidade de situações permanece, e em alguns casos o estatuto dos brasileiros mudou bastante, para melhor ou para pior, nos países de recepção. ${ }^{19}$ Mas acreditamos que a categoria "emigrante" implica certa perda da idéia da especificidade brasileira, ao mesmo tempo que força o brasileiro a se olhar no espelho da imigração, no lugar que cada uma das sociedades de destino procura reservar aos imigrantes.

Reduz-se assim a ilusão do dekassegui que se imagina “meio-japonês" e que idealiza, antes da emigração, uma forma de integração na qual ele não será, no Japão, um estrangeiro "como os outros". Um processo similar ao vivido pelo "brazuca" que, nos Estados Unidos, deixa na prática de ser um transitório (tal como tantas vezes representado, até recentemente) e prolonga sua trajetória migratória numa segunda geração, apontando assim para uma permanência.

A participação dos brasileiros nas recentes manifestações de $1^{\circ}$ de maio nos Estados Unidos, intituladas "Um dia sem imigrantes" e voltadas principalmente 
para as comunidades hispânicas (com as quais os brasileiros sempre evitaram se misturar), mostra que mudanças estão ocorrendo. Caiu no vazio a recomendação do embaixador brasileiro que, em Nova York, recomendara aos compatriotas "não se misturarem aos cucarachas" (Folha de S.Paulo, 20.10.2005).

A própria imprensa começa a noticiar fatos referentes à emigração de brasileiros segundo rubricas e seções nas quais se trata da migração internacional de forma abrangente. ${ }^{20}$ Pensamos que a emigração de brasileiros tende a ser, progressivamente, encarada nos marcos do difícil e instigante contexto das migrações internacionais na atualidade.

Desenha-se cada vez mais a necessidade de um posicionamento da sociedade, e do Estado, no sentido de como lidar com os milhões de brasileiros que partiram e buscam sobreviver no exterior, lá sofrendo todo o conjunto de atribulações comumente associadas à condição de imigrante. A consideração dos seus problemas não pode se limitar ao olhar do exotismo, nem muito menos à expectativa quanto às remessas que envia.

Reconhecer o emigrante como sujeito na construção do Brasil contemporâneo, ainda que situado fora do território nacional, parece ser condição para repensar a nação. Ao explorar algumas das modalidades desse reconhecimento pelos meios de comunicação, procuramos aqui somar a um campo de investigação que muito tem avançado.

\section{Notas}

l Ou seja, com número de saídas superior ao de ingressos, tal como ocorre na atualidade para o caso brasileiro.

2 Um exemplo de análise de discursos veiculados pela grande imprensa a respeito da imigração, para o caso italiano, está em Marcella Delle Donne (2004). Quanto ao caso dos brasileiros nos Estados Unidos, Teresa Sales assinala em <http://www.nepo.unicamp.br/usuario/GerenciaNavegacao.php?caderno_id=491\&texto_id=67l > a feitura de um banco de dados com notícias da grande imprensa nacional e norte-americana e de jornais das comunidades de emigrantes. Não tivemos acesso a esse trabalho.

3 Tais trabalhos, sob a forma de artigos, coletâneas, teses e dissertações, abordaram o tema segundo ângulos e recortes temáticos diversos, enfocando majoritariamente as comunidades brasileiras nos Estados Unidos, seguidos pelos que enfocaram os dekasseguis, trabalhadores brasileiros no Japão, e pelos referentes às migrações fronteiriças (destinadas ao Paraguai, antes de mais nada, mas também a Argentina, Bolívia, Venezuela, Suriname e Guiana Francesa). Os emigrantes em países europeus mereceram até agora uma atenção menor, apesar de alguns poucos trabalhos sobre Portugal, Itália, Espanha e Inglaterra. Considerando a presença crescente de brasileiros emigrantes no continente europeu, tudo indica que esse será um recorte geográfico cada vez mais enfocado.

4 Assis \& Sasaki (2001) realizaram importante esforço de mapeamento e avaliação de toda essa produção. Uma listagem mais recente, com a simples enumeração dos títulos, foi elaborada por Maxine Margolis (s. d.). 
5 Estão incluídos nesse caso os registros de devolução de brasileiros pelos serviços de imigração em aeroportos, mesmo no caso de mera suposição, por parte das autoridades, de tentativa de imigração ilegal. Suposição esta que seria, evidentemente, impossível de ser provada.

6 Optamos por não considerar, para efeitos deste trabalho, a distinção feita por muitos entre contrabando e tráfico de seres humanos. Via de regra, o noticiário não trabalha com tal distinção; além disso, acreditamos ser esta de aplicação polêmica. Ver, a respeito, Bhabha (2005).

7 Entre tais temas encontram-se, por exemplo, relatos a respeito de brain drain, ou saída de profissionais brasileiros qualificados, programas de legalização de imigrantes com referência ao caso de brasileiros.

8 A coleta, feita por nós e por colaboradores diversos, de forma não exaustiva, destinouse a uma lista de notícias na internet, a "Migrações e Sociedade", mantida pelo Núcleo Interdisciplinar de Estudos Migratórios do Rio de Janeiro (Niem-RJ). A maior parte do material examinado encontra-se atualmente nos arquivos da lista, no endereço <http://br.groups.yahoo.com/group/niem_rj/>.

9 As fontes mais importantes foram os jornais de circulação nacional: Folha de S.Paulo, O Estado de S. Paulo, Jornal da Tarde, Valor, O Globo, Jornal do Brasil, O Dia, Zero Hora, Correio Braziliense, que possuem tanto edição em papel como versões eletrônicas. Ao lado desses, buscamos material também em veículos com edição exclusivamente eletrônica: Folha Online, Portal UOL, Portal Terra, BBC Brasil, NoMinimo. Alguns jornais regionais ou locais comparecem também: Correio do Povo (Porto Alegre), Jornal de Criciúma (SC), Paraná Online, Gazeta do Povo (Curitiba), Jornal Opção (Goiânia).

10 A veiculação das notícias sobre o montante das remessas de brasileiros no exterior teve, em 2005, o sabor de uma verdadeira "descoberta" da magnitude do fenômeno da emigração na nossa sociedade e do quanto a economia de inúmeras regiões e cidades já gira em função dessas remessas.

11 As notas seguintes referem-se a reportagens que consideramos significativas, pela abrangência e/ou impacto que obtiveram, mas não representam a totalidade do material examinado.

12 A imprensa ligada à Rede Globo não se furtou a noticiar a polêmica, incluindo mesmo opiniões críticas à telenovela, e não nos parece despropositado arriscar que mesmo essas estimularam a manutenção de um debate extremamente favorável aos níveis de audiência da transmissão. A confusão deliberada entre ficção e realidade pareceu ter sido positiva no objetivo não só comercial, como de pautar o debate político. Pelo menos dois exemplos puderam ser apreciados nesse sentido: o primeiro deles, o "laboratório" que a atriz protagonista teria realizado nos Estados Unidos como imigrante ilegal, e que a fez sentir-se à vontade para avaliar a situação dos brasileiros à luz dessa experiência, dando aliás conselhos a possíveis candidatos à emigração (Folha de S.Paulo, 31.7.2005); o segundo, e mais impressionante, a participação da autora da telenovela, a convite, na audiência pública sobre a emigração brasileira realizada na Comissão de Relações Exteriores do Senado, em Brasília, lado a lado com autoridades de governo e especialistas da academia.

13 Referências à prostituição feminina e masculina (travestis) de brasileiros na Itália e França, juntamente com a organização de redes na exploração dessas atividades, estiveram em BBC Brasil, 20.10.2004, e UOL Noticias, 23.3.2005. 
14 Usamos aqui a expressão "aliciamento" pela sua freqüência no noticiário enfocado. Vale indicar, porém, a existência de discordâncias quanto à pertinência de tal expressão, que enfatizaria uma atitude de subordinação nem sempre verificada. Ver, a respeito, a reportagem (fora do período analisado), contida em NoMinimo, 24.4.2006, <http://nominimo.ibest.com.br/notitia/servlet/newstorm.notitia.presentation. NavigationServlet?publicationCode $=1$ \&pageCode $=54 \&$ textCode $=21983 \&$ date $=$ cur rentDate\&contentType $=$ html $>$.

15 As bibliografias organizadas por Assis \& Sasaki (2001) e por Margolis (s. d.) mencionam uma tese e três artigos em periódicos a respeito de imigrantes brasileiros em Londres.

16 Surgiram na imprensa internacional outras referências a essa migração, porém encontram-se fora do escopo do material analisado para o presente trabalho. Um outro destino para a emigração de brasileiros, que recebeu menção esparsa, foi o da ida de profissionais do setor calçadista para China, fato merecedor de reportagens em $B B C$ Brasil, 7.11.2002, e Zero Hora, 26.6.2005.

17 O uso das palavras "emigrante" e "imigrante" oscilou, no presente trabalho, conforme se tratasse de uma referência predominantemente à sociedade de partida ou de destino. Optamos por uma distinção pouco problematizadora, e estamos cientes do quanto ela poderia se prestar a um debate mais aprofundado. Não houve, porém, espaço para travá-lo dentro dos limites desta contribuição.

18 Vale referir aqui o interessante trabalho de Gian Antonio Stella (2002). Nele, o autor fustiga o preconceito antiimigrante na Itália atual recuperando a história dolorosa de quando os emigrantes italianos eram também tratados como escória por muitas das sociedades para onde se dirigiam. A transição italiana rumo a uma situação de país de imigração poderia ser qualificada sem muito rigor como, de certa forma, inversa em relação à experiência brasileira de transição rumo a um país de emigração. Uma proposta de exploração do caso da Itália está em Helion Póvoa Neto (2005).

19 No caso de Portugal, por exemplo, a questão dos brasileiros se confundia com a polêmica quanto ao estatuto profissional dos dentistas, diferentemente da diversidade das representações atuais, até mais degradantes, posto que incluem com destaque o tema da prostituição.

20 O jornal Folha de S.Panlo criou uma rubrica própria para noticiar fatos referentes a imigrantes no mundo, "Estranhos no paraíso", na qual as notícias sobre brasileiros são incluídas.

\section{Referências bibliográficas}

ASSIS, G. de O.; SASAKI, E. M. Novos migrantes do e para o Brasil: um balanço bibliográfico. In: Migrações internacionais: contribuições para políticas. Brasília: Comissão Nacional de População e Desenvolvimento, 2001. p.615-47.

BHABBA, J. Trafficking, smuggling, and human rights. Migration Information Source, 1.3.2005. Disponível em: <http://www.migrationinformation.org/Feature/display. cfm?id=294>.

DELLE DONNE, M. Um cimitero chiamato Mediterraneo. Per uma storia del diritto d'asilo nell'Unione Europea. Roma: DeriveApprodi, 2004. 
MARGOLIS, M. Bibliography of Brazilian emigration. s. d. Disponível em: <http://sitemason.vanderbilt.edu/files/gdFsQg/Margolis\%20Bibliography._Bib.doc>.

PÓVOA NETO, H. A descoberta da imigração: o caso italiano e a transição no contexto das migrações internacionais. In: X ENCONTRO DE GEÓGRAFOS DA AMÉRICA LATINA, 2005, São Paulo. Anais do X Encontro de Geógrafos da América Latina. Cd-Rom. Universidade de São Paulo, 2005. v.1, p.12052-60.

STELLA, G. A. L'orda. Quando gli albanesi eravamo noi. Milano: Rizzoli, 2002. $277 \mathrm{p}$.

RESUMO - A EMIGRAÇÃO de brasileiros significa algo novo para um país formado historicamente como área de destino para imigrantes. Mais que uma mudança exclusivamente demográfica, essa transição representa um fato social e político que vem sendo progressivamente reconhecido. $\mathrm{O}$ trabalho considera o discurso veiculado na imprensa como uma das fontes de informação que permitem perceber tal mudança e analisa o noticiário referente aos brasileiros no exterior veiculado no Brasil durante o período de 2001 a 2005.

PALAVRAS-CHAVE: Emigração, Brasil, Imprensa.

ABSTRACT - BRAZILIAN emigration means something new for a country historically formed as an immigrant destination. More than exclusively demographic, this transition represents a social and political fact, which is being progressively recognized. This contribution evaluates discourses present in the press as relevant sources of information for the social perception of this change. Thus, it analyzes news and articles about Brazilians abroad that were published from 2001 to 2005 .

KEYWORDS: Immigration, Brazil, The Press.

Helion Póvoa Neto é professor adjunto do Instituto de Pesquisa e Planejamento Urbano e Regional da Universidade Federal do Rio de Janeiro (IPPUR-UFRJ).

@ - helion_povoa@yahoo.it

Recebido em 7.6.2006 e aceito em 18.6.2006. 